\title{
ARTES DIVINATÓRIAS E POESIA: O JOGO DOS TRIGRAMAS
}

Francisco A. Soares ${ }^{1}$

Resumo: A partir da premissa de que as artes adivinhatórias em geral se estruturam como linguagens simbólicas, analiso as consequências a tirar daí lendo e experimentando a poesia de El Juego de los Trigramas $=$ O Jogo dos Trigramas, de Aimée G. Bolaños (2019).

Palavras-chave: Trigramas. Linguagem simbólica. Teoria e crítica literária.

\section{DIVINATORY ARTS AND POETRY: EL JUEGO DE LOS TRIGRAMAS}

Abstract: Departing from the premise that the divinatory arts are generally structured as symbolic languages, my enquiry centers on the various meanings to be yield by interpreting and experimenting with the poetry of El Juego de los Trigramas = The Trigrams Game, by Aimée G. Bolaños (2019).

Keywords: Trigrams. Symbolic language. Theory and literary criticismo.

1 Professor na Fundação Universidade de Rio Grande. E-mail: samfdv6@ymail.com 


\section{I-Ching e poesia}

Muitas "ciências ocultas" estruturam-se como linguagens simbólicas e são manipuláveis a partir das redes conotativas que as organizam. A teia de relações simbólicas que lhes estruturam enquanto discursos, definições e articulações mítico-religiosas é a base do seu funcionamento quando lidas e podem, por isso, dar-se a colheitas estéticas, filosóficas, adivinhatórias, místicas, enfim, nos mais variados gêneros do discurso.

Ao procurar o que nos diz um signo sobre nós, entramos numa teia de conotações em que somos como uma bola sofrendo os efeitos da tacada (no caso, a tacada é o motivo que nos levou à astrologia) dentro da mesa de bilhar. Ao fazê-lo, introduzimos um conteúdo afetivo que vai ser processado por hipercódigos e tabelas que, inevitavelmente, conduzirão a bola a um destino.

No bilhar, é preciso sermos muito bons jogadores para conhecermos o destino (os efeitos todos e seu fim) a partir da tacada; na astrologia (nosso exemplo por enquanto) não. Tal como na poesia, na astrologia, o que interessa é que haja uma leitura que aponte um rumo, mais ou menos sibilino, tanto faz para o caso, mas nunca único: podem sempre coexistir várias possibilidades, as respostas apontando os rumos são, geralmente, ambivalentes e esse rumo é um pequeno código só plenamente executado depois de se passar o previsto, quando o colamos a um acontecimento - com o que, na verdade, o que descobrimos não é o que estava profetizado, mas o que significava aquela predição. As direções que tomamos, os efeitos causados por cada toque nas outras bolas e nos limites da mesa de jogo, nestas "ciências ocultas", estão controlados (estruturados) pela teia de conotações que referi e que funciona articulando-se com os conteúdos que levamos para o jogo. Mas, sabemos que, por exemplo, na astrologia, sendo de determinado signo e ascendente, estamos "condenados" a possuir determinadas características - e as raras exceções estão previstas igualmente. As características e as exceções são os comandos de que dispomos para integrar e processar os conteúdos pessoais. Ao consultarmos a astrologia, levamos-lhe a matériaprima que, adequada a essas características e exceções, produz a "profecia".

A astrologia é, talvez, o mais simples desses jogos - ou, para um leigo pelo menos, o mais fácil de jogar. Essa é a razão pela qual a trago por exemplo. Entretanto, me é útil ainda por outro motivo. Porque vos pretendo sugerir que escrevam um romance. Precisarão de uma estória, com certeza, mas o que não podem mesmo dispensar são os personagens. Muitos romancistas anotam, nas ruas, nos cafés, pessoas e episódios que observam. Por vezes, escolhem uma pessoa e a perseguem até conseguirem definir-lhe uma personagem (perfil) que sirva ao romance ou suscite partes da intriga. Isso é muito trabalhoso e demorado, mesmo que se sinta prazer ao fazêlo. Quando o romancista precisa detalhar mais a personagem, conhecer melhor o seu modo de pensar e de sentir, o processo complica-se. Porém a astrologia pode ajudar, pois ela fornece-nos perfis de personagens em traços gerais e prévios, que toda a gente reconhece. Escolhamos aleatoriamente uma data no calendário para o seu nascimento, com local e hora. Nos nossos dias, a tarefa ainda está mais fácil porque podemos ir à internet e ver se fez sol ou chuva, calor ou frio, naquele dia com o que preenchemos a descrição do momento em que a pessoa nasceu. Podemos facilmente saber que dia da semana era e os acontecimentos coetâneos principais. Podemos imaginar o pai da personagem com o rádio de pilhas a ouvir o noticiário do dia, por exemplo, durante a II Grande Guerra, quando lhe dão a notícia de que era uma menina e nasceu feliz (claro, impossível). Inseridos os dados em um processador, ou em um programa que nos ajude a fazer a carta astral, obtemos uma 
série de características que nos definem o perfil da personagem, de que logo em seguida vamos precisar. O romancista pode acreditar ou não na astrologia. $\mathrm{Na}$ verdade, não precisa acreditar nela, basta-lhe conhecer minimamente como as informações biográficas básicas são processadas nesse sistema modelizante de segundo grau. Talvez a criação dos heterónimos de Fernando Pessoa - para além da fábula que ele próprio fez em torno disso surgindo a partir de um processo mais demorado, os tenha depois definido enquanto personagens a partir de processamentos deste gênero e do seu interesse pela astrologia, pelo tarô, pela cabala, pelo I-Ching ou Livro das mutações (CHERNG, 2015) (sua tradução consensual, apesar do nebuloso histórico de justificações).

Haveria que distinguir aqui entre as "ciências da adivinhação" e as outras, embora todas funcionem da mesma forma perante o mesmo tipo de “combustíveis". A astrologia e o tarô são "ciências de adivinhação". O seu préstimo para o escritor passa mais pelo que eu disse: ajudam a definir um perfil, uma personagem e, até os vários momentos importantes do percurso narrativo, que também podemos encontrar observando a fotografia da mão de alguém, "lendo a mão". Fernando Pessoa, por exemplo, a partir da astrologia, determinou a data da morte de Alberto Caeiro.

As outras "ciências", que não sejam direta ou exclusivamente de adivinhação (mesmo que possam contribuir, ou ser usadas, para isso), desempenham funções estruturantes. Em particular, elas definem tipos estruturais para relacionar personagens (ou perfis), palavras ou frases e símbolos. Não se trata só de colocar conteúdos específicos em jogo numa tabela geral de "comandos" e devolvê-los devidamente enquadrados. Trata-se de definir tipos de relações possíveis, tipos estruturais, que regulam essas e outras muitas operações da mente humana.

O I-Ching, por exemplo, terá definido algumas das dualidades conceptuais fundadoras da Psicologia Analítica e do pensamento de C. G. Jung (1980; 2013) - que estudou o livro durante cerca de trinta anos. Ele não deixa de se prestar às consultas oraculares, mas essa é somente uma de várias aplicações - e, segundo alguns, na origem, nem sequer a principal. A sua estruturação, toda ela assenta no desenvolvimento de dualidades opostas e complementares. Uma vez inseridos, de forma apropriada, os dados no sistema de oposições, as combinações irão se processando em número tendencialmente infinito (mas definível matematicamente) e nos legando "respostas" personalizadas dentro do hipertexto originalmente programado.

Essas dualidades opõem polos ou pontos extremos de uma rede conceptual de grande alcance, por exemplo: masculino-feminino; branco-negro; negativo-positivo; forte-fraco; luminoso-noturno; superior-inferior; côncavo-convexo (introvertidoextrovertido). Quando juntamos a rede a partir dos extremos, interligando-os, eles fecham a totalidade numa simetria, explicando ou enquadrando todas as relações estruturais possíveis no mundo que o paradoxo abarca. No conjunto, as dualidades constituem uma espécie de simetria central (e radial) que, tal como no desenho-matriz do YinYang, se complementam para formar o círculo, a imagem total. O I-Ching estabelece, portanto, as relações simétricas como cânone para interpretação do mundo e da vida.

Ao falar nisto só pretendo exemplificar um tipo de estruturação, que em geometria e desenho podemos intitular assim (simetria central e radial). O que pretendo afirmar é que I-Ching estuda o mundo e processa os conteúdos trazidos por nós através do desenvolvimento de relações simétricas, ou seja, de simetrias e tipos de simetria. Será talvez infinita a extensão das estruturas simétricas em todas as coisas e seres passíveis de desenho no mundo - desde o nosso rosto até aos fractais aparentemente menos comuns. Haverá, também, 
um processamento simétrico das informações nas mais variadas estratégias de planeamento e criatividade. $\mathrm{O}$ nosso próprio pensamento pode ser definido com contra-polar e, por tanto, simétrico. Mas o I-Ching resume tudo nas possibilidades matemáticas e geométricas estabelecidas a partir de uma dualidade inicial: o bloco dos três traços contínuos juntos e o bloco dos três traços interrompidos juntos. A mistura dos dois blocos iniciais, por intersecções, corte e costura, troca de posições, deslocamentos, esquadrinha o mundo, pelo menos o nosso.

É, sobretudo, por aí que relaciono o I-Ching com as artes em geral e a poesia em particular. É claro que a minha aproximação não constitui qualquer novidade, pois o Livro das mutações (CHERNG, 2015) oferece-nos um método de composição, de resto aplicável a todas as artes. Isso me levou, para contrastar, à comparação das minhas reflexões com trabalhos como o de John Cage na música (a partir de 1950-1951) e o que sobre isso foi escrito, por exemplo, em John Cage and Buddhist Ecopoetics: John Cage and the Performance of Nature (JAEGER, 2013). Esses outros trabalhos exploram mais as relações matemáticas, mas são relações e números que, trazidos ao espaço, resultam nas simetrias de que falo.

Pelas suas estruturas simétricas, de uma dualidade simbólica original (a qual deriva da unidade vazia que gera o uni-verso) tiram-se trigramas e hexagramas, multiplicáveis como na reprodução simétrica fractal. O exercício pode-se multiplicar nas mais variadas artes.

Atente-se no aforismo: "da grande tristeza nasce a alegria” (BOLAÑOS, 2019, p. 9). Temos dois polos opostos e um verbo que os torna complementares. É um procedimento que podemos situar nos antípodas do mais comum, nos paralelismos e enumerações da Bíblia - que, no entanto, não desconhece o oxímoro nem o paradoxo. Inúmeras passagens da Bíblia são cumulativas. Veja-se este exemplo do Salmo 35: "cantem e alegrem-se / os que se deleitam na minha justiça / E digam sempre: seja exaltado Jeová". Notamos uma sucessão de reiterações: cantar se define e reitera em alegria, cantar com alegria se determina quando se equipara ao deleitarse na justiça divina exaltando o seu autor - o que, por sua vez, é determinante reconfiguração do próprio deleite. É uma soma que não se desenha por inversões, simetrias negativas ou pares opostos: cantar mais alegria mais deleitar mais exaltar sempre, e só, somas e concordâncias. Entretanto, no aforismo tínhamos uma junção de contrários: grande tristeza-alegria, duas constelações negandose (tristeza, baixo, fraco, recolhido, negativo versus alegria, alto, forte, expansivo, positivo). A Bíblia, como disse, também explora este procedimento, mas é nela mais comum o acúmulo de concordâncias. A linguagem simbólica do I-Ching, por seu turno, trabalha mais a relação de contrários, porque a sua extensa rede semântica assenta, como na imagemmantra Yin-Yang, numa simetria aparentemente inversa (em que a figura de um lado inverte a posição da figura do outro, oposição confirmada pelo preenchimento branco de uma figura e negro da outra). Por isso o I-Ching se dá bem com o zenbudismo e seus microcontos desconcertantes. Os contos zen, habitualmente, criam uma expetativa de que destroem no final encontrando uma solução inesperada que inverte a expetativa.

As simetrias do I-Ching não me parecem tão somente complementares, mas também intermutáveis. Trocando-as de posição geramos novo sentido, mas produzimos igualmente sentido. Além de intermutáveis como totalidades, cada fragmento do Yin e cada fragmento do Yang podem, sem prejuízo, substituir qualquer outro fragmento do seu polo oposto e por aí vamos decompondo e recompondo simetrias dentro da simetria original, em direção ao infinitamente pequeno ou rumo ao infinitamente fractal. 
O pensamento poético opera de igual maneira, com fronteiras variáveis também: por simetrias alternativas de constituintes intermutáveis e substituíveis, podendo reproduzir-se, interseccionar-se e transformar-se até ao infinito, por uma cadeia de operações inversas ou opostas que se reúnem. O que chamamos de poesia lírica funciona quase sempre assim. Podemos isolar um bloco, uma frase, um verso ou grupo de versos, uma simetria ou grupo de simetrias e, depois de isolados, baralhá-los como num jogo de cartas, para distribuir de novo seguindo nova ordem. Com pequenos ajustamentos produziremos novos sentidos poéticos em número indefinível. Isso mesmo foi rentabilizado por práticas aparentemente inimigas: os instantâneos relampejos surrealistas e as programadas alternâncias da poesia visual e concreta. Aliás, desde épocas imemoriais, isso é rentabilizado pelo processo de corte e colagem que, ao mesmo tempo, alimenta as obras literárias e evita os plágios...

Em uma narrativa, os blocos intermutáveis são grandes e constituídos por episódios inteiros ou por cenas, por esquemas inteiros ou partes deles, não propriamente pelas palavras ou frases. Podemos desmontar um episódio e reestruturálo por uma redistribuição das ações ou dos cenários. Contudo, em poesia lírica, faremos isso a cada momento e com quaisquer fragmentos. É essa fácil desmontagem e remontagem que torna o lírico, aparentemente, tão cativante e afável ainda quando fala nas mais dilacerantes verdades e oposições.

O I-Ching estrutura esse tipo de atuação sem nos restringir a criatividade. Cada agrupamento (linha, trigrama, hexagrama) pode mudar de posto numa composição. Dentro dele, cada uma das unidades que o constitui pode-se deslocar também, trocando com outra, como em uma dança em que haja mudança de pares. É claro que o sentido da nova totalidade apontará noutra direção, mas o que interessa é que não deixa de se produzir nem semiose nem estesia. Por essa característica o Livro das mutações (CHERNG, 2015) torna-se tentador para os poetas e lhes fornece uma modalidade operacional exata, mas não repetitiva.

Podemos perguntar-nos agora: como, então, escreveria um poeta sob influência do I-Ching? Se definíssemos uma receita, secaríamos a fonte sem encontrá-la. A pergunta será diversa, penso eu: que arranjos um poeta, conhecedor do Livro das mutaçoes (CHERNG, 2015), organizou que mantivessem cumplicidades estruturais com os desse livro? Podemos encontrar alguns.

Aproveito o exemplo que me está mais próximo neste momento (com a paradoxal amplidão da palavra «próximo»). É simultaneamente uma obra de raro interesse estético, no clímax ou ápice de um percurso biográfico, não só rico, mas interessante para a lusografia e para as Américas. Então vejamos:

\section{Percurso transversal e poesia}

Descendente de guanches, ou pelo menos com antepassados nas ilhas Canárias, entre outras várias ascendências, Aimée Teresa González Bolaños nasceu na cidade de Cienfuegos, na ilha e arquipélago de Cuba, a 16.10.1943 - cerca de um ano depois de Fina (Josefina) García-Marruz (2006) (Badía) publicar o seu primeiro livro (Poemas, tanto quanto li só com três poemas). O seu nascimento se dá no seio de uma família com vínculo forte e conhecido, quer à história do país, quer à sua literatura. A cidade natal fica em uma das margens da baía do mesmo nome, baía fechada, quase um grande lago, que se liga ao mar por uma faixa estreita, começando entre a pequena praia de La Milpa e, do outro lado, pouco mais abaixo, o castelo (um forte) sintomático de Jagua, com suas 
pequenas docas - ambos do outro lado do lago, deixando La Punta de Cienfuegos para trás. É certo que daí partiu cedo, mas foi num tal cenário que primeiro viu a luz, sobre o azul.

Em 1997, ingressou na Universidade Federal de Rio Grande e hoje reside na praia do Cassino, junto à cidade de Rio Grande, que por sua vez assiste à ligação estreita da extensa Lagoa dos Patos com o mar, tendo do outro lado as areias e velhas casas de São José do Norte. Isto é, reside numa cidade cuja envolvência geográfica apresenta fortes semelhanças com a do lugar onde nasceu - retiradas as diferenças de altitude. Pode-se dizer, então, que reside em simetria com o berço.

Para trás de Cienfuegos, dentro da ilha, fica Santa Clara, no centro de Cuba, província de Las Villas. À saída de Santa Clara, indo na direção da mais aberta baía de Buena Vista pela Carretera de Camajuaní, fica a Universidade Central de Las Villas (o nome antigo de Santa Clara e da província, que incluía Villa Clara, Cienguegos e Sancti Spiritus, abrangência da Universidade, de aí conservar até hoje o seu nome). Pouco depois do seu nascimento, Aimée Bolaños foi viver em Santa Clara, onde a sua família tivera presença marcante já, melhor, onde estava o seu berço familiar e social. Nessa universidade se graduou na área de Educação, tornou-se docente e realizou especializações importantes, entre as quais semântica e pragmática (1995), semiótica (1992) e hermenêutica literária (1993). Realizara o doutoramento (1979-1982), entretanto, em Ciências Filosóficas na Universidade de Rostock (no Instituto Latino-americano, sob orientação do grande comparatista Adalbert Dessau).

A Universidade de Rostock foi fundada em 1419, com os estudos canônicos da época e tem, portanto, longa tradição nas Humanidades; no mesmo curso e universidade se doutorou Rudolf Steiner. A cidade, costeira, albergou essa primeira
Universidade do Báltico. Ela se tornara centro de comércio muito importante, como foi Rio Grande, ainda hoje contendo um grande porto que serve todo o extremo sul do Brasil. A cidade de Rostock, voltada para o Báltico, mas protegida pela sua baía, encabeçando o estuário do rio Warnow, foi fundada por comerciantes alemães cerca de 1200 DC e situase hoje na Alemanha (ontem na antiga RDA). A sua localização, junto a essa baía ou lago, portanto, semelhante à Lagoa dos Patos e à de Cienfuegos (um grande lençol de água doce e salgada com apertada saída para o mar), abria para as rotas de um comércio lucrativo, que justificara a Liga Hanseática. Rostock, além de encimar o grávido estuário dessas águas, posicionava-se de frente para a ilha que veio a abrigar Copenhaga. Ela é a maior entre um pequeno grupo de ilhas onde a terra se mescla com o mar, afinando as marés por canais mais estreitos e que permitem passar da Dinamarca para a Suécia quase saltitando. Recorde-se que foi nesse trânsito insular que se instalou Copenhaga muito cedo, talvez no século $\mathrm{X}$, sobre uma pequena povoação pré-existente; recorde-se, ainda, que se tornou capital em 1445, mostrando o fato histórico a importância estratégica do estreito de Ore, por onde o Báltico se liga ao mar do Norte. Do outro lado do canal aparece Malmö (uma cidade com o mesmo número de habitantes que Rio Grande), já em terra firme, que era inicialmente Malmhoug (e dinamarquesa), ou seja, monte de areia. Ambas as cidades, tanto quanto Rostock, devem as diversas fases do seu desenvolvimento econômico ao fato de serem (ou se terem tornado) cidades-porto e pontos de comércio importantes na zona, quer para os que vinham do mar do Norte, quer para os que vinham do Báltico, ou para os que vinham do interior dos países vizinhos, em geral por vias fluviais. O mar Báltico é outro grande lago, ou lagoa, de águas menos salgadas que as do mar do Norte (no qual desemboca e de que recebe o sal) e, menos ainda, que as do Atlântico. Tem essa saída 
estreita, entre ilhas, a de Ore, para o mar do Norte, que por sua vez abria os horizontes econômicos a comércios mais amplos e ricos envolvendo as ilhas britânicas, a colonização da Islândia, o norte da Europa.

A carreira acadêmica de Aimée Bolaños passa também por Ottawa (Ontário), junto ao rio do mesmo nome (nome indígena: Outaouais, que possivelmente significava negociar), próxima de Montréal (Québec) e da fronteira com os EUA.

O desenvolvimento da cidade se deve, mesmo, à sua localização. Numa longa fase inicial, o seu desempenho como porto fluvial (e, mais tarde, com ligações ferroviárias) para escoamento de peles, madeiras e minérios foi decisivo, tornando-a, a partir de 1857 , a capital da província do Canadá estatuto (o de capital) que manteve até hoje. A sua colocação entre o Canadá francófono e o Canadá anglófono a situa, nessa biografia, como um ponto a mais onde viver a diversidade cultural, que as migrações do século XX aceleraram. Recorde-se que Ottawa começou por pertencer à Nova França, passando ao domínio britânico só em 1763 (150 anos depois de ser descrita por Samuel de Champlain). A Universidade de Ottawa (fundada em 1848), onde a poeta é professora adjunta, caracteriza-se (não por acaso) por ser uma universidade bilíngue. A sua relação acadêmica ali passa, de resto, pela participação em encontros científicos ligando universidades e núcleos de estudo Brasil-Canadá, ou Canadá-América Latina, com destaque especial para o Núcleo de Estudos Canadenses da FURG. Nesse Canadá de fronteiras, dualidades, trânsitos e diversidades, Aimée Bolaños deixou descendência até hoje, revisitando o país anualmente.

A sua biografia nos traz ainda notícias de Granada e de Córdoba (Espanha), cidades onde, em tempos, as três religiões do Livro conviveram de forma exemplar, embora provisória. Nelas criou amizades fortes e conheceu de perto o sufismo, dentro do islamismo a corrente que mais se aproxima de uma síntese mística entre a Europa antiga e o seu Oriente.

Por coincidência, tanto a biografia quanto (sobretudo) a carreira acadêmica se desenrolou em torno de cidades-porto, marginadas por águas, em geografias onde mar e terra (ou água e terra) se enrolam um sobre a outra, e vice-versa. Não só, desde o nascimento convive com várias culturas, resultantes de migrações livres ou forçadas (emigrantes e escravos, condenados, fugitivos, aventureiros, marinheiros, negociantes e nobres funcionários públicos de alto gabarito), de culturas elas também enroladas umas nas outras, como terra e mar nas cidades onde, principalmente, vivera a profissão.

Daí, também, resulta que na sua poesia, tanto quanto na ensaística, nos deparamos com palavras e semas migrantes, palavras aladas e viajantes, ou viageiras, abrindo-se pela consciência da alteridade, como notou Carlos Baumgarten (2006) em recensão a Las otras. Ainda essa vivência da diversidade e as leituras que foi realizando, e com que se foi maravilhando ao longo da vida, lhe alimentam uma densa intertextualização, que torna mais alusiva a sua lírica, essencialmente uma lírica em trânsito continuado.

Todavia, entre culturas há muitas procissões e, como nas procissões, instantes preciosos de silêncios. A gente abre-se ao conhecimento de outras sabedorias e procura apreender delas o que nos parece mais proveitoso e mais belo. Entre culturas, ao percebermos estar em contraste a relativa verdade que lhes assiste, cria-se também um silêncio de que igualmente nos aproveitamos e que nos mantém despertos, acordados, sensíveis às outras vozes. Acho que é deste silêncio entre músicas ou culturas, em que se nos impõe a consciência do não-dito nem expresso [De qué, silencio, eres tú silencio? (MARRUZ, 2011)], é daí que vem a combustão que faz a poesia lírica de Aimée 
Bolaños aberta, com o sentido de uma totalidade que se fecha sempre mais adiante, ou mais longe...

Escrevendo, geralmente, em castelhano (ou espanhol), ao fim de uma intensa e prolongada vivência em Rio Grande e na sua Universidade (FURG), publica pela primeira vez uma série de líricas em português, melhor, em espanhol e português, edição bilíngue para a qual a sua experiência e sagacidade como tradutora certamente contribuíram. Com tal bilinguismo se dá a sua entrada poética na língua portuguesa. Claro que essa entrada na semiosfera da língua portuguesa operava-se, também ela, muito por leituras e vivências anteriores. Eram leituras ao mesmo tempo entusiasmadas e críticas, olhando para as obras como poeta e como coletora ideal, encontrando as equivalências e as impossibilidades de tradução. Disso mesmo dão conta as análises, conferências, ensaios e livros de ensaios. Quem a pode conhecer de mais perto, animando círculos de poesia e declamação, conversando sobre os mais diversos autores, apercebe-se de que o leque de fascínios importantes com a poesia em língua portuguesa (e também com a narrativa) é muito mais vasto do que deixam perceber os seus ensaios, aliás, argutos e afinados por focalizações teóricas não dogmáticas.

A pertinência da sua poesia para o meu propósito aqui deriva, em primeiro lugar, da publicação do livro O jogo dos trigramas (BOLAÑOS, 2019), feito a partir do I-Ching, que a autora lê e exercita há muitos anos. A biografia resumida, quer pela formação (nela se destacando a semiótica, a hermenêutica e o exercício crítico da leitura), quer pela abertura que revela perante novos contextos e culturas diversas, transforma o livro num meio promissor para experimentarmos as nossas hipóteses e devolve-nos, pela qualidade estética, o prazer da poesia - esse desfrute sublime que nenhum teórico até hoje definiu.

\section{Estruturação poética do jogo dos trigramas}

O próprio livro se apresenta como um "jogo-oráculo", no qual a parte oracular é mais de autorrevelação (para cada leitor) através da arquitetura simbólica proposta em aberto (não propriamente limitada aos 64 hexagramas ou, neste caso, trigramas). Os seus trigramas líricos, por "combinações mais lúdicas que oraculares, de autoconhecimento e projeção fantástica, talvez o mesmo" (BOLAÑOS, 2019, p. 9), convidam-nos a prosseguir o jogo. Sim, talvez o mesmo e também nesse nível a resultante da lúcida constatação: "para aquele que leva em si a grande imagem, todas as coisas convergem [...]".

No português e no espanhol de hoje temos esta palavra "coisa" ("cosa") a fazer de bola de basket, pobre e maravilhosa a um tempo, conforme o jogador. Ela indica, lembra o dicionário Houaiss, "tudo o que exista, ou possa existir, de natureza corpórea ou incorpórea”. Não propriamente o verdadeiro, mas o real, pois o verdadeiro é verdadeiro para o homem (vir) e o real é real para todos, incluindo os animais das fábulas, é real em si. Dentro desse tudo-nada, certamente alado, cabem muitas especificações ainda... A sua próxima origem estará no latim, sendo a mesma de "causa", mas indicando o que é de fato. Na linguagem jurídica, se dizia com propriedade: "de fato e de direito" (ou seja, de re e de regra). A grande imagem é a grande causa, por isso todas as imagens (coisas-cosas) convergem para ela. E assim se quer aquele famoso círculo do Yin e do Yang, para o qual tudo converge e do qual deriva tudo - como ele do Universo e o Universo do vazio.

O livro se organiza em octógono, correspondendo cada parte a cada uma das "oito figuras simbólicas do I-Ching (Céu, Trovão, Água, Montanha, Terra, Vento, Fogo, Lago)". As figuras simbólicas do I-Ching, matriciais, constituem polos 
de simetrias e, portanto, concentrações de motivos, tópicos e temas. É “dentro de seus temas" que "são escritos oito trigramas" (BOLAÑOS, 2019, p. 9), os tais que os leitores combinarão ludicamente em hexagramas que podem chegar a ser oraculares no que diz respeito à sondagem de nós próprios.

Esta característica - da combinação livre e inquiridora das unidades mínimas - é, como escrevi anteriormente, um traço típico da lírica. Podemos ver isso combinando as mais diversas frases e versos de cada trigrama com frases e versos de outros trigramas, da mesma parte ou de outra parte, extravasando para fora dos limites do jogo proposto pela autora sem contradizer as suas regras. O único limite estético é o de que se formem novas unidades igualmente belas e legíveis (em se tratando de poesia mesmo, todas as unidades de chegada, por efeito das de origem, serão belas). O carácter aberto a conotações e combinações operadas pelos leitores, próprio da poesia lírica, realiza-se aqui no seu ápice de concentração, de concisão e de correspondente disponibilidade de sentido.

Experimentemos com dois trigramas poéticos encontrados aleatoriamente ao abrir o livro:

\author{
Aniquilada entrego-me \\ a um descenso sem fim \\ e na queda ascendo \\ (BOLAÑOS, 2019, p. 23).
}

\section{Ante ti em êxtase}

sou essa mulher com asas

seduzida por teu abismo

(BOLAÑOS, 2019, p. 61).

Podemos extrair os versos e reunilos cruzando alternativamente os trigramas e compondo hexagramas. Exemplo:

\author{
Ante ti em êxtase \\ aniquilada entrego-me \\ sou essa mulher com asas \\ a um descenso sem fim \\ seduzida por teu abismo \\ e na queda ascendo
}

Fazendo esse exercício podemos gerar poemas ou hexagramas em número enorme, como já se demonstrou pela construção de geradores textuais no começo da arte cibernética ou informacional, a qual sempre se relacionou bem com a complexidade matemática e fractal do I-Ching. Porém aqui temos um condicionador estruturante ou esse outro hipertexto que, por sua vez, é ao mesmo tempo totalizante e aberto: o Livro das mutações (CHERNG, 2015) e seu símbolo octogonal básico, transformável em diversas combinações articuladas, nessa complexidade que pretende abarcar todas as situações possíveis do extenso texto do mundo multiplicando o número por si próprio. É um jogo ideal para a poesia, cumprindo o requisito estético desde que se escolham bem as frases ou versos iniciais - as unidades que entrariam no gerador textual. O seu hipertexto (no sentido informático da palavra) possibilita a personalização, tanto quanto o atirar para longe, que faz com que todo o poema digno desse nome nos deixe uma sugestão mais forte, mais intensa, de algo que não ficou inteiramente escrito e que, por vezes, outro poeta procura reescrever.

A arte visual, aproveitada para a capa e acompanhando o começo de cada "figura simbólica" ou seção do livro, demonstra, num campo artístico diferente, algumas das potencialidades da personalização que refiro. Nesse caso, temos uma combinatória menos matemática, por outra via, de acordo com a tradição chinesa, aquela via que nos avisa da necessidade de pintar 
ou desenhar o kanji, seguindo regras (de cima para baixo, da esquerda para a direita), mas acolhendo o irrepetível de cada traço humano instantâneo. Os kanji-transformações, as figuras simbólicas de Miguel Elías, na sua absoluta autonomia equiparável à dos trigramas - acompanham da melhor maneira o livro, recordando-nos as oposições complementares (por exemplo por simetrias de cores) e completando-o ao frisar a personalização que se opera ao mesmo tempo em que se converge.

Temos então um livro que se estrutura sobre simetrias e dualidades (oito "figuras simbólicas" preenchidas por oito trigramas em grupos de quatro pela distribuição gráfica nas páginas, numa totalidade assente em números pares), as quais por sua vez se reúnem em número de três ou seus múltiplos (os trigramas e os hexagramas, que podem por sua vez entrar como dualidades também). O conjunto perfaz as mesmas numerações e, portanto, a mesma estruturação de cada (octogonal) "figura simbólica".

Já temos, então, duas influências do I-Ching na estruturação da obra: o Livro das mutações (CHERNG, 2015) ajuda a organizar a temática (motivos, tópicos e temas de cada "figura") e a matemática, geometrizada sem dúvida, formando os oito capítulos ou secções e respetivas peças únicas. Essas peças únicas, esses átomos líricos, são por sua vez decomponíveis em seus elétrons, prótons e nêutrons. Elas não se compõem pelo método de colagem que nos levou ao hexagrama anterior, aliás, eu não sei como se compuseram, mas os sinais que nos deixa a autora, na exposição inicial, não apontam para aí. Esses átomos líricos, decomponíveis e remisturáveis (logo, redimensionáveis), eles é que são a matéria-prima, a frase-verso-estrofe-poema que um cibernético escolheria para introduzir no seu gerador textual. O gerador textual somos nós e é a nossa leitura criativa que se estrutura a partir das sugestões do
I-Ching atiradas pela obra para os olhos atónitos, abertos, em clave di nós.

Há, ainda, uma terceira "influência", menos perceptível e menos exata, que vamos encontrar no interior de cada verso dos trigramas, na sua distribuição sintática e lógica ao mesmo tempo, quando fazemos a decomposição em elétrons, prótons e nêutrons.

Comecemos por essa regra básica segundo a qual os contrários se atraem. Portanto, seguindo a mesma metáfora atómica, as cargas negativas (elétrons) e positivas (prótons) atraem-se. Formase, então, o paradoxo, melhor, a relação dos contrários. Por exemplo, neste verso, colhido ao acaso (BOLAÑOS, 2019, p. 47):

\section{Avanço de costas}

O "avanço" é positivo, "costas" é a negação do avanço. Temos dois polos diferentes e um espaço de interrelação (no caso, pela preposição "de", evocando o modo). O "de" é a força de atração entre o próton (o "avanço") e o elétron ("costas"). Se traduzíssemos para uma linha de trigrama, daria numa linha quebrada ou fraca, traço-espaço-traço (geralmente associada ao feminino, à sensibilidade, à lua):

Há outros versos-linhas que podemos aproximar do traço forte, contínuo, do trigrama (geralmente associado ao masculino, ao sol, à afirmação). Por exemplo, na mesma página,

\section{Sem ataduras}


ou na seguinte:

\section{da vida}

Entretanto, há versos-linhas em que podemos encontrar duas partes - uma linha fraca, portanto, ou quebrada - que, porém, como no caso da Bíblia citado mais acima, se combinam, cumulam, reiteram, ou não se contradizem, por isso equiparando-se também a um traço contínuo, masculino, forte. Ainda na página 47:

\section{Alada é a viajeira}

ou na seguinte, reiterando pela negativa:

\section{Nada sei nem me posei}

ou, na página 55:

\section{Abrir à vida}

ou na página 61:

\section{Amorosos se unem}

Releio agora um trigrama inteiro, por exemplo, o primeiro da página 37:

ou na página $23:$
Para voltar bastaria

um rastro oculto lá longe

distância significa volta

A primeira linha não se contradiz, equivale a um só traço, a dois protões ou um prótão (próton) e um neutrão (neutron). Já as duas seguintes unem paradoxos: "um rastro" mostra, portanto, opõese à ocultação; a "distância" separa, enquanto a "volta" reúne. Conotam esses dois versos, portanto, duas linhas quebradas ou fracas. Encontramos, ao desenhá-los, um trigrama assim:

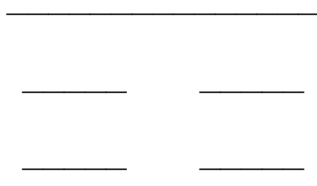
uma rede semântica ligando "quietude, imobilidade; é o filho mais novo. Parte do corpo: mão. Animal: cão.” Por acaso, ou talvez não, é o trigrama $\mathrm{V}$ da seção «Montanha».

Uma vez dadas as indicações, o leitor continuará exercitando o jogo...

\section{Referências}

BAUMGARTEN, Carlos A. A Escrita Poética de Aimée Bolaños e a questão da identidade. In: Letras de Hoje, Porto Alegre, v. 41, n. 4, p. 72-82, dez., 2006.

BOLAÑOS, Aimée G. El juego de los trigramas = O jogo dos trigramas. Rio Grande: FURG, 2019. 
BOLAÑOS, Aimée G. Las otras: antologia minima del silencio. Madrid: Torremozas, 2004.

BOLAÑOS, Aimée G. Las palavras viajeras: poemas. Rio Grande: FURG, 2010.

BOLAÑOS, Aimée G. Oficio de lectora. Rio Grande: FURG, 2016.

CHERNG, Wu Jyh. I Ching: O Tratado das Mutações. Rio de Janeiro: Mauad, 2015.

JAEGER, Peter. John Cage and Buddhist Ecopoetics: John Cage and the Performance of Nature. London ; New York: Bloomsbury, 2013.

JUNG, Carl Gustav. Psicologia do Inconsciente. 2. ed. Trad. Maria Luiza Appy. Petrópolis: Vozes, 1980.

JUNG, Carl Gustav; WILHELM, R. O segredo da flor de ouro: um livro de vida chinês. 13. ed., trad. Dora Ferreira da Silva e Maria Luiza Appy. Petrópolis: Vozes, 2013.

MARRUZ, Fina García. El peso de las cosas en la luz: antologia poetica. Sel. e prólogo de Susana Cella. Buenos Aires: Colihue, 2006.

MARRUZ, Fina García; BARRIONUEVO, Carmen Ruiz. ¿De qué, silencio, eres tú silencio? Salamanca: Universidade de Salamanca, 2011.

Submissão: abril de 2020 .

Aceite: outubro de 2020. 